\title{
Manipulative Function of Corporal Media
}

\author{
Zoran Aracki \\ PhD, prof., University in Nis, Faculty of Philosophy, Nis, Serbia, \\ zoran.aracki@filfak.ni.ac.rs \\ Andrej Blagojevic \\ Student PhD, University in Nis, Faculty of Philosophy, Nis, Serbia, \\ andrej.blagojevic@yahoo.com
}

Doi:10.5901/mjss.2014.v5n13p461

\begin{abstract}
The changes that have happened lately in Balkan media put in front the corporal journalism, which instead of being in service of citizens more often is becoming the powerful weapon of media owners. The journalism paradigm, according to which it is supposed to serve all of the citizens, in modern conditions, it slowly transforms into open serving to capital owners and bearers of ideological power. No doubt this endangers the foundations of democracy. Instead of rule by the people it turns into dictatorship of corporal elite, whereas media by constructing of conceivable, narcissistic and esthetic narrative seduce public opinion. Analyzing in structure more complex, but also in content more unified sphere of media activity, the author focuses on developing abyss between rich and poor on the Planet, deducing how new media philosophy into the society center instead of citizen as a subject puts the consumer as the object of the public. Insensibly the character of journalism has been changed: in corporal society it becomes corporal itself.
\end{abstract}

Keywords: media, corporatism, ownership, democracy, ideological power

\section{Introduction ${ }^{1}$}

Transition of East European states which started two decades ago, with the Berlin Wall fall brought major changes in this area to nations in all life spheres, also in that referring to media. Perennial reality was changed, from socialism to capitalism, with dominant ideology of neo -liberalism.

In such changed circumstances, media politics was directed to making of independent and democratic forms, and independence was defined was as termination of the state influence on media. Media changed ownership, from the state hands moved to private capital world. The privatization was mostly performed in opaque manner, which often lead to appearance of corruption affairs, and also to creation of monopoly because it was not taking care about concentration of media ownership.

Today, here the relations between media and politics, that is the state have been significantly changed. Several big world media companies from Germany, Switzerland, Scandinavian countries, and also United States have bought many the most circulated and influential media in these countries. On markets of Serbia, Bulgaria, Macedonia, Croatia, Bosnia and Hercegovina and Romania, for many years the most present company has been German VAC. Today it is Switzerland Ringier. As for domestic media owners, they have been mostly recruited from the class of so called businessman, that is people who, until the change of regime have been in favor of former socialist leaders.

It was expected that the change of ownership in media would bring in more freedom, more investigative journalism, more analytic texts, but this has not happened. The journalism paradigm, according to which it has to serve to all citizens of the world, in modern circumstances, slowly turns into open serving to capital owners. Thus the foundations of journalism profession have been endangered, and also the democracy itself.

\subsection{Topic, aims and basic hypothesis of the work}

Due to all this, in this article, we will analyze the changes that have happened in modern journalism in the countries of Southeast Europe with special attention to Serbia. Our aim is to point to the fact that changed media philosophy in the

\footnotetext{
1 This article is the part of the Project No. 179074, completed by Center for sociological Research at Faculty of Philosophy University in Nis financed by the Ministry of Education of Republic of Serbia.
} 
center of society puts a consumer as an object of the public instead of a citizen as the subject. The world is actually at the crossroads, because manipulative and in this way directed communication indicates the hidden mass tyranny, which seduced by planned, strategic calculations and technologically powerful impacts think and act in the way the tailors of the spiritual weaving prepare in their corporal workshops.

American liberal dogma which is the most present in the countries of Southeast of Europe promoted the new market rules and wealth as the life ideal. Its domination was especially supported by the transformed media, which by constructing of persuasive narcissistic and aesthetic narratives very successfully mastered the public opinion in these countries. However, here is still talked about serving the general, public interests, but more often it is about open serving to capital owners and through them the bearers of ideological power.

Hence, the starting hypothesis in this article, counting on the corporations' power and ideology of corporatism is that the journalism itself has become corporate, in other words the part of the new power structures. The new ownership elites by media pictures in the mind of auditorium are embedding the projected meaning ${ }^{2}$ so as to by spinned placed terms blunt the critical awareness and offer the desired sense. All the time amusing-tabloid forms are forced, and critical investigating approach is pushed on the margins. The openness of the order where everything may be said is demonstrated by the opening of new papers, magazines, journals, radio and TV stations, numerous blogs and social networks. Moreover, many media mean much scattered attention, which recipients brings less time for thinking and search for solutions. ${ }^{3}$

\subsection{Applied methodology}

In this article we applied many different methods and research techniques adopting them to our topic and objectives. The most common is the method of media content analysis, by which we tried to point the ways the media in the hands of new owners have been creating the general picture of society we live in. By comparative method we compared the media practice in several Balkan countries. We applied series of other methodological proceedings: from speculation of experience research to introspection of social media role observation, to analysis and synthesis of media contents. By using of historical, normative and analytic method, we obtained the scientific research on the question on changed, mostly manipulative function of media in Southeast Europe countries. By the synthesis method we formulated the conclusions and on them defined the recommendations we consider important for establishment of social more responsible media position.

\section{Findings}

\subsection{Profit and group interests}

The establishment of the ownership type of media happened in the middle of sixties of the last century when corporations, suddenly started buying shares of prominent newspapers. "The trigger was Wall Street revealing of the most kept secret of the American press...that the most of daily papers are profitable" (Bagdikian, 1992:11-12). Most of great American newspapers, such as "New York Times", "Washington Post" or "Los Angeles Times" were founded in $19^{\text {th }}$ century. The founder was "the powerful Patriarch" who knew the job, extraordinary entrepreneur, he managed on greatest challenges, Adolf Ochs, for example, 1986 bought "The New York Times" for $\$ 75,000$, and the company, seven decades later was worth millions.

After The Second World War, $80 \%$ of daily papers in United States of America were diversified in family ownership, but 1989, the proportion was reverse - 80\% of ownership was corporate. Or, in 1981, 20 corporations owned 11000 magazines, and seven years later the number of owners was - three (Bagdikian, 1991:14).

Ben Bagdikian, in the sixth edition of "Media Monopoly" in 2000 ( and the edition is the fact, because the numbers were reduced from edition to edition) asserted the trend: "In 1983, fifty corporations controlled most of mass media, the greatest "merging" (connecting, enlarging companies) in the history cost 340 million dollars... In 1987 remained twenty nine of fifty companies... In 1990 from twenty nine the number was reduced to twenty three... In 1997 were ten, and the business of Disney- ABC, the greatest until that time was worth 19 billion dollars... In 2000 the merging of AOL-Time Warner reached as much as 350 billion dollars which is 1000 times greater amount then the greatest business in

\footnotetext{
${ }^{2}$ According to definition of Stuart Price "the meaning is the reference, event or activity by which the sense os transferred to people" (Piece, 2011:21)

${ }^{3}$ Roman philosopher Seneca explained this two thousand years ago with these words: "To be everywhere means to be nowhere".
} 
1983..." (Bagdikian, 2000: xx-xxi).

Accordingly, there are fewer players, as Mother Jones magazine published by the end of 2006, that eight big media companies provide majority of Americans with news and information (Disney, AOL-Time Warner, Vicom, General Electric - owner of NBC, New Corporation, Yahoo). Afterwards, it was talked about five companies. "Fewer players, less freedom", intellectuals claim critically (Shah, 2009). Bagdikian explained that such a few people may sit at one table, make agreement about everything and that they in reality make private Ministry of Information. Although it formally does not exist, the consequence is obvious - western media easily harmonize about following of important events. "Actually... they function in this way, as they get instructions from some managerial center such as CC KPSS (Zinovjev, 1999:52).

Warner A. Meier, the member of Euro Media Research Group and the professor in Zürich, determined that, apart from "ten colossal conglomerates dominating the global media market", this phenomenon is very little examined. Meier quotes the American researcher Christopher $\mathrm{H}$. Sterling that "it is surprisingly little of research - and they are mostly marginal... Most of are the assumptions or anecdote like remarks or mere results presentation about ownership" (Meier, 2002:209). This is not strange because of the social media industry role which "plays important role in identifying of inequality in wealth, power and privileges. When the flow control of information, knowledge, values and images is in hands of those who share the power with dominating class, then this class can define what will circulate in mass media with the intention to maintain the structure of class inequality which it has the benefit of" (Meier, 2002:299)

Alas, in the nineties of the last century, liberal- democratic world clashed with sinister reality that the theory on press freedom was most often formulated in the way to protect media owners. That is why it is " a little odd to represent the view that private ownership of media guarantee the right of each citizen to broadcast any content. In the approach to media based on political economy it is pointed that private business interest in media restrains in the same way the freedom of speech as much as different forms of limitations imposed by governments" ( Chambers, 2007:128). The Political economy theory (the corpus of opinions and researches of predominant inquirers from the end of the last century) starts from that the giant corporations treat news as merchandise "which aim is to gain the profit for its shareholders". The consequences are that "cheap amusing shows, such as quizzes, in program schedule are in advantage in relation to quality documentaries", as long as "new form of investigation journalism focused on consumers. At present, number of magazine-type shows are made, in which are offered pieces of advice and exposes about different domestic and everyday topics such as holidays, food, mortgage on real estate and personal finance" (Chambers, 2007:136-137).

In such changed circumstances, entertainment took over in media the greatest space and doubtlessly influenced the essence of the journalism itself. Michael Eisner, former "Walt Disney Company" General Manager, on internal meetings used to say: "We are not obliged to history. We are not obliged to art. We are obliged to massage. To make money is our only aim" (Shah, 2009).

From the old model in which it was thought about democracy and called to the First Amendment, conventions and codes, and money took from under the table, entered the model of cartel in which only interests of connected persons and groups are important. Media organizations in Southeast Europe are " mostly owned by big transnational corporations which connected control over financial interests not only in telecommunications, entertainment industry and tourism but also in oil industry, paper production, real estate and nuclear industry" (Chambers, 2007:131).

Thus, by global commercialization of media, at the end of the last century, the awareness on general interest was lost, and information started to be treated as means for high profit achievement and mass seducing. ${ }^{4}$ In Southeast Europe countries appeared many new media, but in them messages are standardized with the use of identical value system. What is the basic change is the appearance of tabloid forms and tabloid media. Today, it is all the same whether one in hands holds Belgrade Politika (Serbia), Zagred Jutarnji List (Croatia), Skopje Dnevnik (Macedonia), Sofia Trud (Bulgaria), Sarajevo Dnevni Avaz (Bosnia and Hercegovina) or some similar widely circulation newspapers from the country of Southeast of Europe: information is template, look alike each other as peas in a pod, there are most of the big pictures, easy topics... media reports in them are more often results of political settlements between elite of media owners and elite of government, and this is more than obvious. In Romani, once the German VAC as the owner of widely circulated paper "Romana Libera" gave to journalists " Guide to writing" according to which they should not "criticize too much" the ruling party. ${ }^{5}$

\footnotetext{
${ }^{4}$ Jevtovic, Z. (2013): Corporal Capitalism and Media Seducing, Yearbook Facu of Culture and Media, year V, Belgrade, pg 398 ${ }^{5}$ More of that Aracki, Z.(2010): Media Transition in Globalization Era, Belgrade: Institute for Political Studies, pg 9 


\subsection{Elite Symbiosis}

Corporatism is the real master of global processes. Hiding under it auspices, in the complex capital society, government spreads charisma on its democracy, does not accept any criticism on own responsibility for social standard decrease, increase of unemployment, ecological devastation of the Planet, military compulsion, sanctions and similar punishment forms of disobedient nations. Almost all important information is selected first, worked out and constructed according to wishes of the corporate elite, but it is not publicly recognized. Everything is hidden behind different serials such as "Big Brother", "Farm" and similar which impose the life models. In television program in the Southeast Europe countries, according to our research, such and similar series take more than $60 \%$ of the signal time broadcasting.

Corporate techno-structures are the owners of global media companies, and by appointing of managers, especially editors, on responsible posts, they fulfill the dream on communication space total control. This is mostly appropriate to authority structures, especially in Southeast Europe. For, at the time of traditional print, radio and television "gaining of approval"6 was simpler and easier, because by the censorship of texts or electronic contents provided control easily. Internet and social networks increasingly popular in the countries of Southeast of Europe enable each man to interpret in his own way, create, control and monitor conflicts, events, problems. Hence, the authority elite needs monitoring over media reality, which is structured of the myriad information and meanings of which in many countries it could not respond. Responsibility and quilt are implanted into one party, and alternative opinions fall behind from globalized media.

Totalitarian regimes in this part of the world went from the global stage relatively peacefully, with the important mission of western propaganda which created conditions for ideological movement gradually changing the Eastern Block citizens' mind. The temporary global system is composed of the regions, corporations, religions, invisible organizations, interest oligarchies and political movements, with the high level of communication interdependence. There is more truth, for domestic and foreign public, according to interests of those in whose hands are the reins of the communication management. The modeling of the world according to new patterns is founded on camouflaged ideas of political domination, military hegemony and unconcealed arrogance towards those who think differently.

Governments, not only in Southeast Europe, but in other countries as well, use mostly the connections of authority elite and media ownership elite in order to put under the control the influential media, directly influencing the formation of public opinion. The citizens' right " to know everything" is more declarative than real, but in order for the masks not to fall down too soon , the narrative about democratic capacities of public services which " no one can influence on" is created. In practice, politicians combining legal certifications and close connections with the tops of media corporations, with the help of big advertisers manage the communication space. In Hungary, the Prime Minister Victor Orban with the change of the law significantly narrowed the space for independence of state media; in Croatia the law on HRT was changed so the first man is to be elected by the Parliament; In Serbia the set of media laws is announced to be changed; In Slovakia the change of authority majority lead to the change of public TV service director although the Parliament Board for Culture and Media unanimously adopted her report on work...

Corporatism is the shadow of actual changes, the true winner of missed ideologies, ${ }^{7}$ real master of global processes. In complex capital society, authority spreads charisma about its democracy, hiding that it does not include any criticism of own responsibility ( decrease of living standard, unemployment increase, ecological devastation of the Planet, military compulsion, sanctions and similar punishment forms of disobedient nations and so on). Almost all important information are selected first, worked out and (re)constructed according to wishes of the corporate masters, but it is not publicly recognized. The freedom ritual is camouflaged with the "care and responsibility" for the safety of each individual, and when rare lonely once speak about Big Brother and about monitoring of all communication flows, the ordinary man is suspicious about sincerity of such intentions. The object of manipulation is the last to know that is the subject of manipulative activities, believing that the given message is true. Something similar happened at the time of Nazism. Hitler promised to worker "disempowerment of the means of production", while at the same time the factory owners were guaranteed "protection before the strike". Both believed him, because he controlled their subconscious: pictures of hope

\footnotetext{
${ }^{6}$ Noam Chomsky revealing propaganda model under the control of state bureaucracy, register five filters that censor information contents: "1) size, ownership and profit orientation of mass media;2) marketing activity and influence of advertisers; 3) news source; 4)" anti-aircraft artillery" and attacks on media; 5) ant communism as monitoring mechanism" (Chomsky, 2004; 153-207)

7 "The main power of all fascism variations between two World Wars - there were different forms from Mussolini's originals, via Hitler's national socialism to Roosevelt's liberal Fascism - was in corporatism. That appearance and that term is very important for the future of democracy and capitalism, because the corporal power will outlive the fascism, mutate in after war societies, fasten its position in the cold war which gave significant part of legitimacy for its functioning and be taken over as social-economy base from the key power of 20th century -USA". (Reljic, S.(2014): Crisis of the Media and Media Crisis, Belgrade: Official Journal, pg 105).
} 
for better tomorrow arouse masses from the lethargy, pre election noise totally suppressed rationality, and with the crisis impoverished Weimar Republic believed in mystique phrases on chosen people. Ever since almost has nothing changed in elite intentions- only technologies became faster, more sophisticated, more convergent, more persuasive.

Traditional links that only more than one decade ago bind citizens of Southeast Europe states for ethnic, social or cultural origin with the technological revolution suddenly weakened giving the space to growing information tide. Established corporal media, as priority see only their own and the interest of the authority elite, and are ready to replace the professional reputation with the stacks of bills which for short time provide strategic positioning on the market.

\section{Conclusion}

Modern civilization is ruled by interwoven mass media networks along which flow myriad of the same and similar contents, making foundations of global economy and politics. Print, electronic media, publishing houses, movie companies, public relations agencies, telecommunication and computer industry form firm and universal information ring which encompasses the Planet. The world is in turmoil: the power of muscles is replaced by the power of mind, instead of force and coercion it is ruled by information and propaganda. In difference from the states of industrial society, incentive of the third wave is created ${ }^{8}$ which needs great amount of energy, food and - information.

In corrupted journalism the perception is with plan moved from experience and facts to imagination and announcements, producing transformation that deprives reality of the truth value. Knowledge about others is created though memory because only images are remembered. ${ }^{9}$ The power of symbols theoretically belongs to the public sphere, which should be independent and free, but with liberal concept and understanding that information is only merchandise as all other commence the battle for monitoring and imposing. The idea on general interest in media of Southeast Europe is significantly marginalized, because it is more than clearly imposed fact that information is the source of profit.

In the era of twenty four hour news distribution, journalists less and less search, check and investigate. Mostly, they only retell what comes to them from influential power centers. When the story is made it is transferred further in the way that many call "the logic of the herd". Investigative journalism is defeated, and the idea that media serve to ordinary people, is equal to a dream about democracy as an order of free and equal people. Modern media in the countries of Southeast Europe today represent commercial and political institutions which have the interest on the first place, while the truth is desirable only when it is in accordance with dominant corporal interest. Burdened with economic difficulties, for most often they work for extremely low salaries, without health and pension insurance, journalists accept their changed role. In this way is changed the character itself of the journalism which in the society ruled by big multinational corporations becomes corporate itself.

\section{Proposals}

Estimating that the corporate journalism seriously imperiled the foundations of journalist profession, we are free to propose the new model of media system functioning.

The model starts from three attitudes - (Hypo)thesis;

1. That media is the product and producer of modern society;

2. That choice of role of media model in society depends on global social development model;

3. Choice (orientation) for social-democratic model of transition with social responsibility represent that autonomy of each part of the society (it also means media system) is the condition for democratic integration of the whole and its successful social development.

Having in mind these starting hypothesis and principle, we may point that the draft of democratic model of media role in modern society, with which the manipulative role of media would be reduce at the lowest possible level has to have the following determinants, characteristics:

a) Dominant shareholders form of ownership, which would make journalist co-owners and co-managers, responsible for the professional image and competitiveness of media;

b) Autonomy of editorial-in relation to political and ownership sphere;

c) High professionalism of journalist (affirmation of ethics and occupation);

${ }^{8}$ Tofler, Alvin\& Hajdi (1998): War and Anti War, Belgrade: Paidea, pg.292

9 "Memory allows us to hear what is unheard and to see what is invisible. Hence, I repeat, no wander if a soul, which keeps in itself what it is not anymore, adopts that what it has not been yet; because it suits it more and is closer to it: it throws and stretches into future, and that what passed and is finished it freed and kept it only in memory", remarked Plutarch (Pythian Dialogues, 1990, pg 83) 
d) Participation, as a form of co-decision of all employed in media system;

e) Market competence and verification of competitive ability and social profitability.

All these elements in their union in the model of media system in social practice may make it more quality and more efficient in relation to hitherto models and promote media as responsible actor in society in the function of objective informing and forming of the critical citizen public, without which there is no responsible and democratic society.

\section{References}

Aracki, Z. (2010): Media Transition in Globalization Era, Belgrade: Institute for Political Studies.

Bagdikian, B. H. (1983): The Media Monopoly: Beacon Press.

Chambers, D. (2007): A Critical Approach to Media - the context change of investigative journalism, Belgrade: Clio (essay in chrestomathy Investigative Journalism, edited by Hugo de Berg).

Chomsky, N. (2004): Politics Without Power, Zagred: DAF.

Jevtovic, Z. (2013): Corporal Capitalism and Media Seducing, Belgrade: Yearbook Faculty of Culture and Media, year V.

Meier, W. A. (2002): Media Ownership - Does It Matter? ( in book Networking Knowledge for Information Societies: Institutions \& Intervention - edited by Robin Manssel, Roham Samarajiva and Amy Mahan. Delft: Delft University Press.

Plutarch (1990): Pythian Dialogues, Novi Sad: Matica Serbian.

Price, S. (2011), Media Studies, Belgrade: Clio.

Reljic, S. (2014): Crisis of the Media and Media Crisis, Belgrade: Official Journal

Tofler, A.\& H. (1998): War and Anti War, Belgrade: Paidea.

Zinoviev, A. (1999): A major Milestone -Critique of Western Hegemony, Belgrade: Nas dom - L'age d'Homme. 